\title{
EDITORIAL
}

\section{The July phenomenon: why don't we see it in obstetrics?}

\section{Journal of Perinatology (2007) 27, 71-72. doi:10.1038/sj.jp.7211643}

In July of my intern year of my 4-year residency in Obstetrics and Gynecology, I was assigned to the community midwifery service. As an obstetrician-in-training, I was excited to learn the art of obstetrics from a group of clinicians who have particular expertise in providing care in the labour and delivery setting. During my second week of the rotation, I went in to evaluate a woman who had been in labour for several hours. She was experiencing painful contractions and wondering how long this might go on. I performed a cervical exam and noted her to be completely dilated. I discussed this finding with her and her husband and explained that she could begin pushing.

After writing my note, I went to the nurses' station to find my preceptor, an excellent, experienced, midwife who had taken me through several deliveries the previous week. I told her the great news; she was quite surprised to hear that our patient had progressed so rapidly to complete dilation. We went back to the labour room, and she performed her own cervical exam, during which she had expression on her face that was a mix of both thoughtfulness and amusement. 'Well, you aren't quite fully dilated yet,' she said to the patient, 'but you are completely effaced.' In fact, our patient was only $1 \mathrm{~cm}$ dilated and not particularly happy to hear that she was not ready to push. I was surprised to learn that in some women, their cervix and lower uterine segment can efface so that upon first exam it feels as if the foetal head has no cervix remaining in front of it, but actually, the cervix is far posterior, only to be reached by a vigorous exam.

Every June, more than 20000 medical students graduate in the United States. They have spent 4 years concentrating on the science of medicine, but they are novices in the art of medicine. The art of thoughtfully applying the science that they have studied is to be learned during their internship and residency beginning in July. Thus, seemingly, July is the time when the most inexperienced clinicians are caring for patients in teaching hospitals. Such timing has been conjectured to produce a 'July phenomenon' of decreased quality of medical care and worse patient outcomes. ${ }^{1}$

The existing literature has examined the question in a variety of settings including inpatient medical services, ${ }^{2}$ intensive care units ${ }^{3}$ and obstetric wards. ${ }^{4}$ Interestingly, the majority of these studies have demonstrated that outcomes do not appear to be worse in July. However, one study demonstrating no decrement in outcomes found that house staff inexperience appeared to be associated with increased costs. Finally, a recent paper on the topic demonstrated both increased costs and decreased quality of care - the July phenomenon, as described. ${ }^{6}$

In the current edition of the Journal of Perinatology, Ford et $a l^{7}$ examine this question in the setting of obstetrical care. They utilize a large administrative data set to examine whether a battery of outcomes are worse in July and demonstrate no difference between July and other months of the year. The strengths of their study include the various obstetric outcomes they examined and the statistical power they had to find even small differences in these outcomes.

Given these authors' finding of no differences in obstetric outcomes, the question for them is why? Overall, it does seem that health-care costs are higher in July, so perhaps the hospitals expend more resources to compensate for inexperienced residents. However, I would propose that these increased costs are simply due to the greater inefficiency of care provided earlier in a physician's training which may lead to excess laboratory or radiologic tests ordered and longer lengths of hospital stay.

Actually, I believe the primary reason that there may be no transient decline in the quality of care as measured by medical complications is increased surveillance by more experienced supervising clinicians at this time of year. Particularly in obstetrics, where there are attending physicians in-house and present at every procedure during both day and night in teaching hospitals, I do not find it particularly surprising that there is no difference in measured outcomes. While there may be differences in patients' experiences such as concern for being 'practiced' or 'learned upon', the presence of those clinicians ultimately responsible for both educating the residents and caring for the patients ensures that the overall quality of care is not affected. Thus, one future direction for research might be measures of patients' satisfaction throughout the year.

In the years that have passed since internship, I have become one of these supervising clinicians and have had to explain to patients why cervical exams between providers may vary quite a bit when my enthusiastic interns overestimate an exam. With attention to the experience of those we are educating, we can provide comprehensive care to our patients that minimizes complications. With this in mind, I will frequently cite this paper by Dr Ford and her co-workers to the patients I care for and use its information to reassure them that while their care will be provided by both residents and medical students, I do not believe that the presence of medical education will decrease the quality of their care. 
AB Caughey

Department of Obstetrics, Gynecology and Reproductive Sciences, University of California, San Francisco, San Francisco,

CA, USA

E-mail: abcmd@berkeley.edu

\section{References}

1 Blumberg MS. It's not OK to get sick in July. JAMA 1990; 264: 573.

2 Rosenthal GE, Harper DL, Quinn LM, Cooper GS. Severity-adjusted mortality and length of stay in teaching and nonteaching hospitals. Results of a regional study. JAMA 1997; 278: 485-490.
3 Barry WA, Rosenthal GE. Is there a July phenomenon? The effect of July admission on intensive care mortality and length of stay in teaching hospitals. J Gen Intern Med 2003; 18: 639-645.

4 Myles TD. Is there an obstetric July phenomenon? Obstet Gynecol 2003; 102 1080-1084.

5 Rich EC, Gifford G, Luxenberg M, Dowd B. The relationship of house staff experience to the cost and quality of inpatient care. JAMA 1990; 263 953-957.

6 Huckman RS, Barro JR. Cohort turnover and productivity: the July phenomenon in teaching hospitals NBER working paper No. 11182. March 2005, JEL No. I1, J0, pp 1-42.

7 Ford AA, Bateman BT, Simpson LL, Ratan RB. Nationwide data confirms absence of 'July phenomenon' in obstetrics: It's safe to deliver in July. $J$ Perinatol 2007; 27: (in press). 